\title{
DFT Study, POM Analyses and Molecular Docking of Novel Oxazaphosphinanes: Identification of Antifungal Pharmacophore Site
}

\author{
Khadidja Otmane Rachedi', Rania Bahadi ${ }^{1}$, Mohamed Aissaoui ${ }^{1}$, Taibi Ben Hadda ${ }^{2,3}$, Billel Belhani ${ }^{1}$, \\ Abdeslem Bouzina ${ }^{1}$, and Malika Berredjem ${ }^{1, *}$
}

${ }^{1}$ Laboratory of Applied Organic Chemistry LCOA, Synthesis of Biomolecules and MolecularModeling Group,

Badji-Mokhtar - Annaba University, Box 12, 23000 Annaba, Algeria

${ }^{2}$ Department of Pharmaceutical Chemistry, Faculty of Pharmacy, Umm Al-Qura University,

Makkah Almukkarramah, Saudi Arabia

${ }^{3}$ Laboratoire de Chimie des Matériaux, FSO, Université Mohammed 1er, Oujda 60000, Morocco

\section{* Corresponding author: \\ email:malika.berredjem@univ-annaba.org}

Received: May 29, 2019

Accepted: July 21, 2019

DOI: $10.22146 /$ ijc. 46375

\begin{abstract}
A computational Petra/Osiris/Molinspiration/DFT(POM/DFT) based model has been developed for the identification of physico-chemical parameters governing the bioactivity of series of oxazaphosphinanes derivatives 1a-1f containing potential antifungal O,N-pharmacophore. A molecular docking study was performed in order to evaluate synthesized compounds, their possible antifungal properties, and their interactions in the binding site. Molecular docking studies revealed that the compounds 1a-1f have the potential to become lead molecules in the drug discovery process. The six compounds $\mathbf{1 a - 1 f}$ analyzed here were previously synthesized by our group.
\end{abstract}

Keywords: oxazaphosphinane; DFT; Petra/Osiris/Molinspiration (POM) analyses; molecular docking

\section{- INTRODUCTION}

The 6-membered P-heterocycles have attracted considerable attention from the scientific community because of their wide biological activities spectrum [1]. Examples cited in the literature include oxazaphosphinanes 1 with antiproliferative properties [2-3], azaphosphinane 2, which has been shown to be effective as a biodegradable insecticide [4], and antitumoral [5-6] as alkylating agent drugs such as cyclophosphamide and ifosfamide 5, 6.

Research teams have described the synthesis of a series of oxazaphosphinane 3 , an analog of hydroxybupropion, which has been evaluated as an antidepressant agent [7]. In the past 20 years, significant effort has been devoted to the synthesis of a particular family of organophosphorus compounds: such as 4 [8] and ( \pm )2-aryl-3,3,5,5-tetramethyl-[1,4,2]-oxazaphosphinanes 7 [6].

Among methods used of quantum mechanics, density functional theory (DFT) methods that have been widely used in many studies because of the smaller computational resources needed to describe very large systems. Specially, they have been found to be efficient in the description of systems dominated by hydrogen bonding interactions [9].<smiles>[X]C1C(O)C(O)C(O)OP1(=O)O</smiles>

1<smiles>O=P1(N(CCCl)CCCl)NCCCO1</smiles>

5<smiles>O=P1(c2ccccc2)CCCCN1Cc1ccccc1</smiles>

2

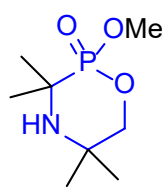

3

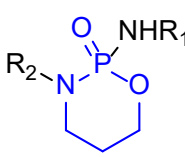

4

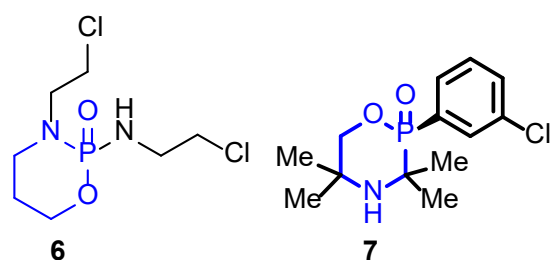

7

Fig 1. Examples of important bioactive oxazaphosphinanes and their derivatives 


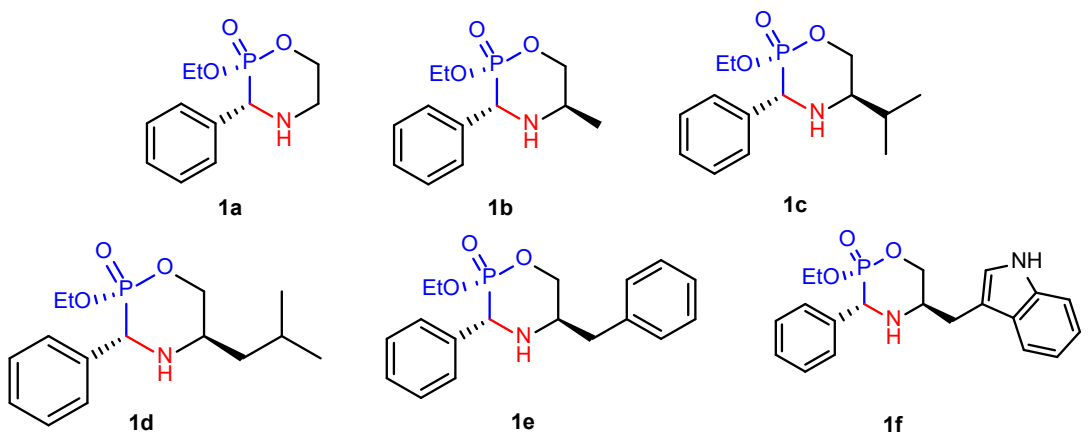

Fig 2. Chemical structure of studied compounds

Recently, DFT has been accepted by the quantum chemistry community as a cost-effective approach for the computation of molecular structure, vibration frequencies, and energies of chemical reactions. Many studies have shown that molecular modeling has had a profound effect on procedure modeling through a better understanding of the fundamental physical and chemical interactions, through forming the basis for predicting physico-chemical properties of molecules that are difficult to calculate using experimental procedures [10].

The most important orbitals in determining chemical reactivity are the highest occupied molecular orbital (HOMO) and the lowest unoccupied molecular orbital (LUMO). The energy difference between the HOMO and LUMO, means the band gap, can sometimes be useful to measure of the molecule excitability, the smaller energy, the more easily it will be excited [11-14]. In the past few years, there have been some theoretical studies of oxazaphosphinane using molecular modeling [15-16].

The aim of our work is the theoretical study of reactivity and to determine energies, dipole moments and vibrational study of six novel oxazaphosphinanes [17] (Fig. 2), using the density functional theory method (DFT). POM (Petra/Osiris/Molinspiration) analyses have been executed with the aim of evaluating the performance of physic-chemical properties of tested compounds. As a result, an antifungal $\mathrm{O}, \mathrm{N}$-pharmacophore site is identified. A docking study was carried out to achieve the interaction on the active site.

\section{- COMPUTATIONAL METHODS}

The studied compounds were optimized with DFT by program package GAUSSIAN 09 using the B3LYP/6-
31G(d) method. The B3LYP density functional method is one of the most commonly Hybrid functional used, which stands for Becke, 3 parameters, Lee-Yang-Parr [18]. We employed well established in silico tools POM Osiris, Petra, and Molinspiration, validated with about 7000 drug molecules available in databases [19].

The inaugural molecular docking program, DOCK, developed by Kuntz and co-workers, has a long history of new advances and accomplishments in the field of structure-based design. We briefly present methods for preparing the system and performing pose reproduction experiments in the program DOCK. First, the molecular surface of the receptor absent hydrogen atoms and the ligand was determined using the DMS [20] program, then, the DOCK accessory programs sphgen [21] and show box were used to generate spheres and box within the ligand binding site. The DOCK accessory program GRID [22] was used to precompute energy interactions between a dummy probe atom and all receptor atoms on a $0.3 \mathrm{~A}^{\circ}$ resolution grid within the box. Finally, for pose reproduction experiments, the ligands were treated as flexible based on the FLX protocol (standard flexible docking) by Mukherjee et al. [23].

\section{- RESULTS AND DISCUSSION}

\section{DFT Studies}

The molecular geometry of oxazaphosphinanes and the nature of their substituents are often correlated with their stability and their reactivity. In order to specify the relationship between the experimental results of the activities with the structure of the molecules and to evaluate this relationship, theoretical studies were carried out by molecular modeling. Thus, modeling 
gives some important and necessary information on the structure and reactivity of oxazaphosphinane.

\section{Geometry optimization}

The optimization of different structures has been obtained by Gaussian 09 [24] using the B3LYP/6-31G(d) [25-26] method. The optimized geometries were used to calculate the level of energy HOMO, LUMO, and gap. The structures of the six compounds obtained after geometric optimizations in the DMSO solvent are shown in Fig. 3.

The values of hydrophobicity coefficient $(\log \mathrm{P})$ thus energetic levels of the (HOMO, LUMO), gap energies, total energy, dipolar moment $(\mu)$ and linear polarizability
$\left(\alpha_{\mathrm{Tot}}\right)$ calculated by DFT method using B3LYP/6-31G(d) in the gas phase and DMSO solvent are presented in Table 1.

The compound 1e has the highest gap energy in both gas phase and DMSO; it is more stable and less active. In the gas phase, $\mathbf{1} \mathbf{a}$ is the more active compound, while in the DMSO solvent, the more active compound is 1f. The results in Table 1 show that the gap energy ( $\Delta \mathrm{E}$ gap) is inversely proportional to the dipolar moment.

\section{Chemical reactivity}

In order to understand the activities of titled compounds, the conceptual density functional theory (DFT) was employed to obtain the chemical reactivity

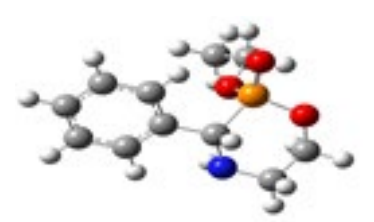

1 a

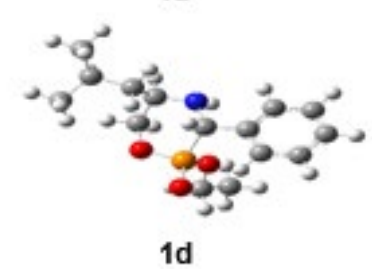

1d

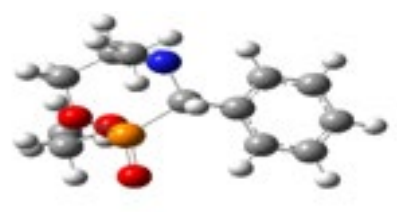

1b

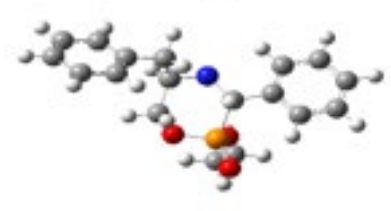

$1 e$

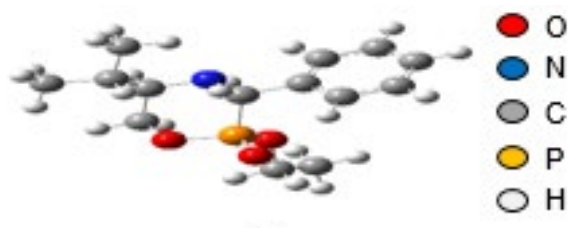

1c

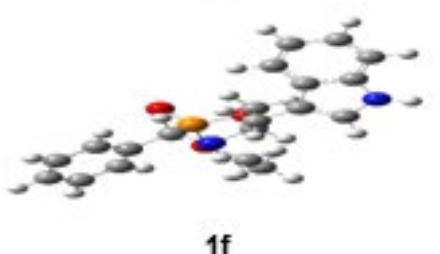

Fig 3.Optimized structures of titled compounds obtained at B3LYP/6-31G(d) level in DMSO

Table 1. The calculated parameters of compounds 1a-1f obtained by the B3LYP/6-31G(d) method in the gas phase and DMSO solvent

\begin{tabular}{|c|c|c|c|c|c|c|}
\hline \multirow{2}{*}{$\begin{array}{l}\text { Descriptors } \\
\text { Molecule }\end{array}$} & \multicolumn{6}{|c|}{ Gas phase } \\
\hline & $1 a$ & $1 b$ & $1 \mathrm{c}$ & 1d & le & 1f \\
\hline $\log p$ & 1.87 & 2.29 & 3.16 & 3.84 & 3.97 & 3.28 \\
\hline$\alpha_{\text {Tot }}\left(\right.$ Bohr $\left.^{3}\right)$ & 141.33 & 151.78 & 173.78 & 185.18 & 211.95 & 239.34 \\
\hline$\mu(\mathrm{D})$ & 4.0263 & 3.9571 & 3.9546 & 3.9755 & 2.7887 & 6.9136 \\
\hline $\mathrm{E}_{\text {номо }}(\mathrm{eV})$ & -6.41399 & -6.42216 & -6.40964 & -6.40175 & -6.54788 & -6.23957 \\
\hline $\mathrm{E}_{\text {LUMO }}(\mathrm{eV})$ & -1.37717 & -1.34179 & -1.32792 & -1.33227 & -0.69688 & -0.86342 \\
\hline$\Delta$ Egap $(\mathrm{eV})$ & 5.03683 & 5.08037 & 5.08173 & 5.06948 & 5.85099 & 5.37615 \\
\hline $\mathrm{E}(\mathrm{u} . \mathrm{a})$ & -1050.634 & -1089.9483 & -1168.573 & -1207.884 & -1320.994 & -1452.557 \\
\hline Descriptors & \multicolumn{6}{|c|}{ DMSO } \\
\hline Molecule & 1a & $1 b$ & $1 c$ & 1d & 1e & 1f \\
\hline$\alpha_{\text {Tot }}\left(\right.$ Bohr $\left.^{3}\right)$ & 182.41 & 196.09 & 224.11 & 237.84 & 272.91 & 313.01 \\
\hline$\mu(D)$ & 5.8327 & 5.8691 & 5.7702 & 5.8942 & 4.5032 & 10.0717 \\
\hline $\mathrm{E}_{\text {номо }}(\mathrm{eV})$ & -6.64230 & -6.64067 & -6.64012 & -6.64203 & -6.59033 & -6.27278 \\
\hline $\mathrm{E}_{\text {LUMO }}(\mathrm{eV})$ & -1.59704 & -1.57799 & -1.57173 & -1.57363 & -1.30506 & -3.10917 \\
\hline$\Delta$ Egap $(\mathrm{eV})$ & 5.04526 & 5.06268 & 5.06839 & 5.06839 & 5.28527 & 3.16360 \\
\hline E (u.a) & -1050.648 & -1089.962 & -1168.587 & -1207.898 & -1321.008 & -1452.577 \\
\hline
\end{tabular}


descriptors, using the HOMO's and the LUMO's energy level (Fig. 4).

Electronegativity, noted $\chi$, is a chemical property that describes the ability of an atom to attract a shared pair of electrons (or electron density) towards itself [27]. Chemical hardness [28], noted $\eta$, is a measure of the resistance to change the electron cloud density of the chemical system, its reciprocal softness, noted S. The electrophilicity index, noted $\omega$, is used to measure the stabilization in energy when the system acquires an additional electronic charge from the environment [29]. These different values are illustrated in Table 2.

Table 2 shows the reactivities of the new molecules. According to this, the compound 1e has the highest chemical hardness and is more stable. In addition, the most active compound is $\mathbf{1 a}$ in the gas phase and $\mathbf{1 f}$ in

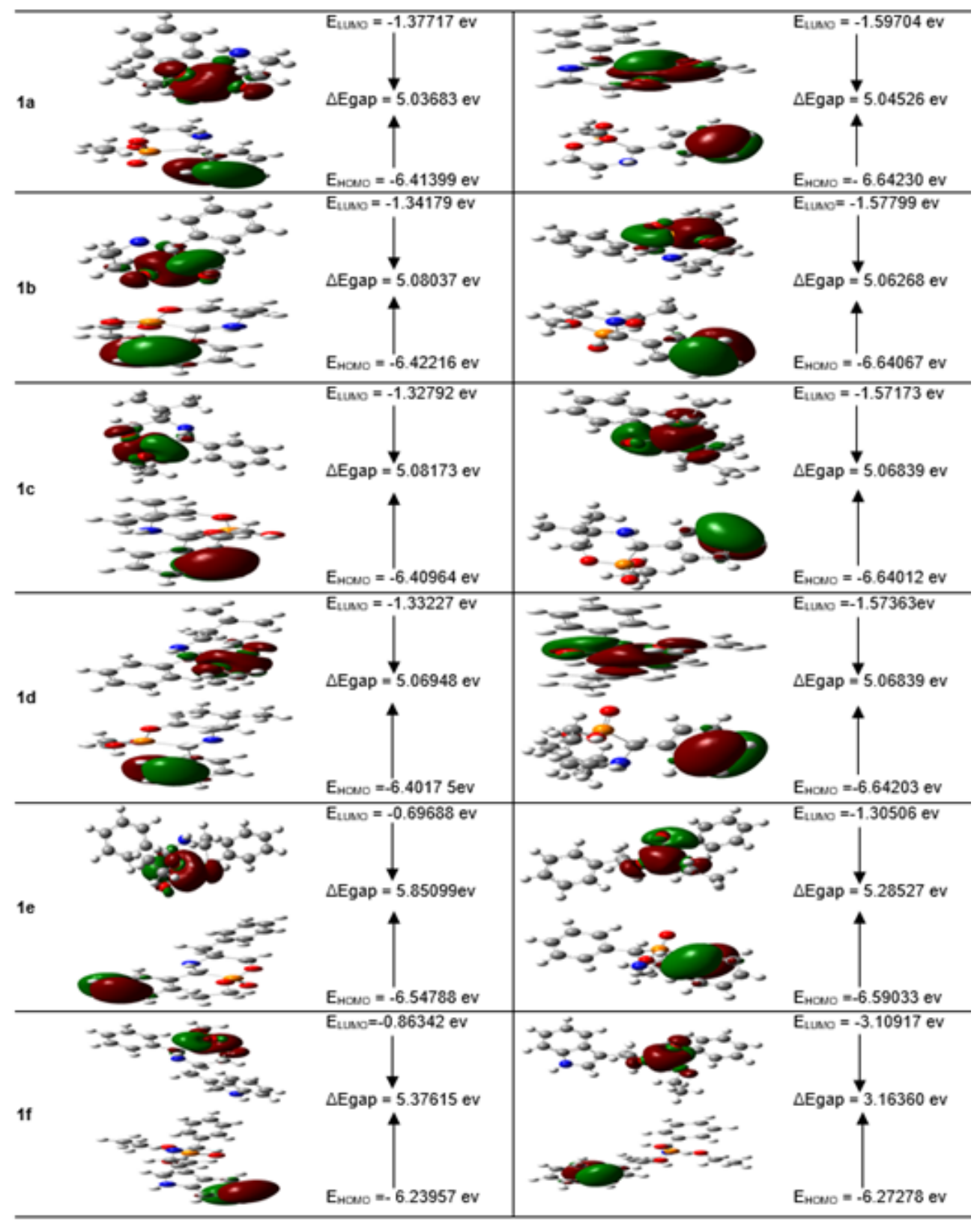

Fig 4. HOMO, LUMO orbitals and their energy gap ( $\triangle$ Egap) for 1a-1f obtained at the B3LYP/6-31G(d) level using a contour threshold of 0.02 a.u in the gas phase and DMSO solvent 
Table 2. Calculated values of chemical hardness, electronegativity, Electronic chemical potential, and global values electrophilicity index for the compounds studied by B3LYP/6-31G(d)

\begin{tabular}{|c|c|c|c|c|c|c|c|c|c|c|}
\hline & \multicolumn{5}{|c|}{ Gas phase } & \multicolumn{5}{|c|}{ DMSO } \\
\hline & $\eta$ & $\mathbf{s}$ & $\mu$ & $\chi$ & $\boldsymbol{\omega}$ & $\eta$ & $\mathbf{s}$ & $\mu$ & $\chi$ & $\boldsymbol{\omega}$ \\
\hline $1 a$ & 2.5198 & 0.3969 & -3.8967 & 3.8967 & 3.0123 & 2.5226 & 0.3964 & -4.1198 & 4.1198 & 3.3633 \\
\hline $1 b$ & 2.5415 & 0.3935 & -3.8831 & 3.8831 & 2.9660 & 2.5306 & 0.3952 & -4.1089 & 4.1089 & 3.3361 \\
\hline 1c & 2.5415 & 0.3934 & -3.8695 & 3.8695 & 2.9443 & 2.5334 & 0.3947 & -4.1062 & 4.1062 & 3.3252 \\
\hline $1 d$ & 2.5361 & 0.3943 & -3.8667 & 3.8667 & 2.9497 & 2.5334 & 0.3947 & -4.1089 & 4.1089 & 3.3307 \\
\hline 1e & 2.9252 & 0.3419 & -3.6218 & 3.6218 & 2.2422 & 2.6422 & 0.3785 & -3.9483 & 3.9484 & 2.9497 \\
\hline 1f & 2.6885 & 0.3720 & -3.5511 & 3.5511 & 2.3456 & 1.5810 & 0.6325 & -4.6912 & 4.6912 & 6.9552 \\
\hline
\end{tabular}

DMSO. In the gas phase, the compound 1a has the highest $\omega$ and $\mu$ values, so it is the most susceptible molecule to nucleophilic attack.

\section{Molecular electrostatic potential surface}

The electrostatic potential maps are the energy of interaction of a positive charge (an electrophile) with the nuclei and electrons of a molecule. Negative electrostatic potentials indicate probable initial sites for the electrophilic attack. Enough small value of the electron density gives overall molecular size and shape. The electrostatic potential can be mapped onto a particular value of the total electron density by using color to represent the value of the potential. The regions of the molecule with negative values of the electrostatic potential are indicated by red color, while color blue indicates positive values of the potential. The green color corresponds to an intermediate potential situated between the two extremes (red and dark blue). The yellow and light blue color split the difference between the medium color (green) and the extremes (red/dark blue).

Based on these considerations, oxygen would be related with the red region of the diagram, and nitrogen would be found with the blue region; the phosphorus, carbon, and hydrogen situated between these two extremes, phosphorus in the yellow region and the green region for carbon and hydrogen (Fig. 5).

The molecular electrostatic potential's representation of title compounds that the oxygen atom (red region) presents the electrophilic attack site with high electron density; furthermore, analysis of the NBO charge in DMSO shows that phosphonyl oxygen atoms have an average charge of -0.871 in all compounds except in 1e -0.864 and

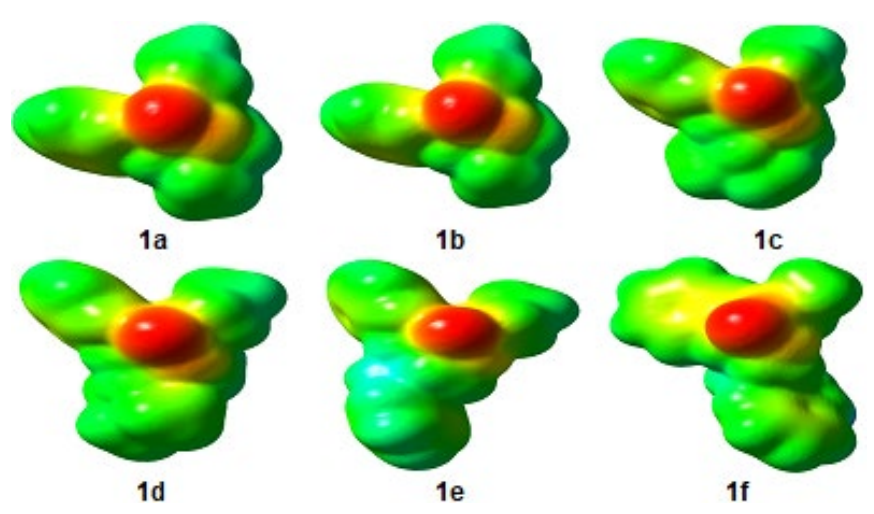

Fig 5. Molecular electrostatic potential MESP for titled compounds on total density (Isovalue $=0.0004 \mathrm{a} . \mathrm{u}$ )

-0.869 in $\mathbf{~ I f}$, as well as nitrogen amide, carried a charge of -0.699 in $\mathbf{1 a},-0.704$ in $\mathbf{1 b},-0.703$ in $\mathbf{1 c},-0.702$ in $\mathbf{1 d}$, 0.702 in $1 \mathbf{e}$ and an average charge of -0.629 in $\mathbf{1 f}$. On the other hand, MESPs shows one major nucleophilic active centers at the proximity of hydrogens atoms related to nitrogen atom, with a NBO charge of 0.399 in 1a, 0.401 in $\mathbf{1 b}, 0.403$ in $\mathbf{1 c}, 0.401$ in $\mathbf{1 d}, 0.409$ in 1e and an average charge of 0.428 in $\mathbf{1 f}$, and another nucleophilic center in all compounds due to the presence of ethoxy group.

\section{POM Analyses of Compounds (1a-1f)}

For a molecule to be a potential drug, besides having a good biological activity, it must have good pharmacokinetic properties in human biological systems. To access the pharmacokinetic profile of the tested compounds, we employed Petra/Osiris/Molinspiration (POM) analyses. The results of theoretical toxicity risks of compounds 1a-1f, which are calculated with the aid of the Petra/Osiris/Molinspiration (POM) program are shown in Table 3 [30-32]. Our findings reveal that all 
synthesized compounds 1a-1f, are not toxic and can be utilized as therapeutic agents.

Interestingly $\mathbf{1} \mathbf{b}$ deserves pharmacomodulation (DS $=47 \%)$. The hydrophilicity character of each compound has been calculated. All of the compounds (1a-1f) have accepted $\operatorname{cLog} P$ values $(\operatorname{cog} P<3)$. The geometrical conformation of pharmacophore site is taken into consideration (Fig. 6). This is because it is flexible for all compounds (1a-1f). The absorption, distribution, characteristics, and bioactivity were proved to be dependent on the geometrical parameter and the aqueous solubility of each compound.

On the other hand, drug-likeness (DL) of (1a-1f) is not in the comparable zone with the used standard drug. The compounds (1a-1f) showed a high capacity to excellent DS as compared with Ifosfamide (Table 3 ).

Topological polar surface area (TPSA), i.e., surface belonging to polar atoms and molecular weight, is the descriptors that correlate with passive molecular transport through membranes that allow prediction of the route of transport of drugs through the barrier membranes the intestine and blood-brain barrier (BBB). All tested compounds have no violation of Lipinski rules $(\mathrm{NV}=0)$. Prediction results of compounds (1a-1f) with molecular properties (GPCRL, ICM and enzyme inhibitors) are recorded in Table 4.

\section{Molecular Docking Study}

From the previous results of the POM program, and with the aim of achieving the interaction on the active site, a docking study was carried out. Computer-based molecular docking can facilitate the early stages of drug discovery through systematic prescreening of ligands (i.e., small molecules) for shape and energetic compatibility with a receptor (i.e., protein) prior to experimental evaluation [33-35]. Recently, small chemical ligands have been reported to inhibit cytochrome P450 sterol 14a-demethylase in a wide spectrum of fungal species [36-38]. To understand the mechanism of action and antifungal activity of our synthesized analogues, molecular docking studies were employed using the crystal structure of human cytochrome P450 2E1 that was picked from the Protein

Data Bank (CYP2E1; pdb code: 3e4e) (http://www.rcsb.org/pdb). The protein was processed, optimized, and minimized by using the protein preparation wizard of Schrodinger Suite by applying OPLS3 force field [39].

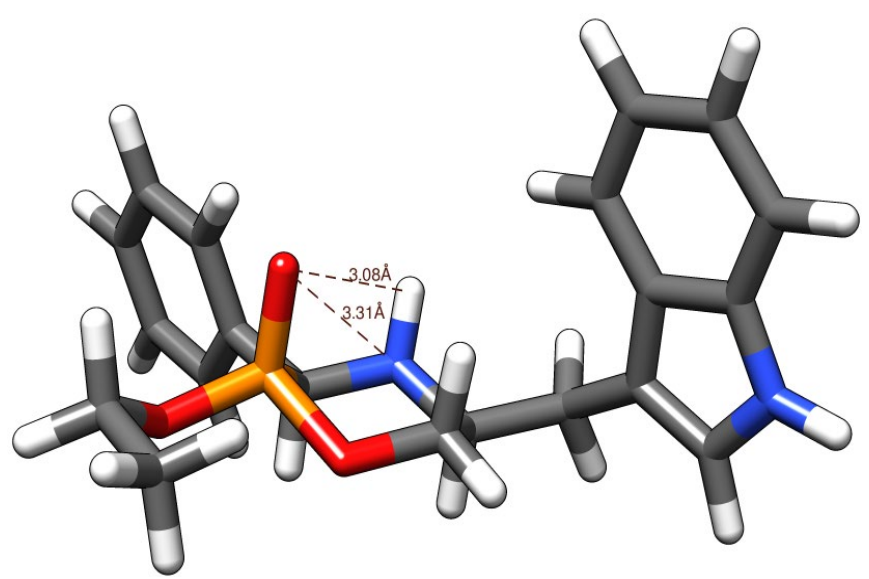

Fig 6. Identification antifungal $O, N$-pharmacophore site of compound $\mathbf{1 f}$

Table 3. Osiris calculations of toxicity risks of compounds (1a-1f)

\begin{tabular}{|c|c|c|c|c|c|c|c|c|c|}
\hline \multirow{2}{*}{ Compounds } & \multirow{2}{*}{ MW } & \multicolumn{4}{|c|}{ Toxicity Risks $^{[\mathrm{a}]}$} & \multicolumn{4}{|c|}{ Osiris calculations $^{[\mathrm{b}]}$} \\
\hline & & MUT & TUM & IRRI & REP & $\operatorname{cLog} P$ & cLogS & $\mathrm{DL}$ & DS \\
\hline $1 a$ & 241 & 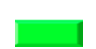 & 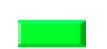 & 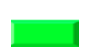 & 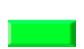 & 1.01 & -1.93 & -30.92 & 0.47 \\
\hline $1 b$ & 255 & $\square$ & $\square$ & $\square$ & $\square$ & 1.34 & -2.31 & -29.71 & 0.47 \\
\hline 1c & 283 & $\square$ & 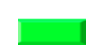 & $\square$ & $\square$ & 2.01 & -2.74 & -31.38 & 0.45 \\
\hline $1 d$ & 297 & 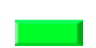 & 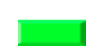 & 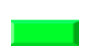 & 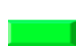 & 2.46 & -3.01 & -30.71 & 0.43 \\
\hline 1e & 331 & 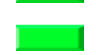 & 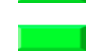 & $\square$ & 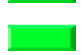 & 2.78 & -3.44 & -30.32 & 0.41 \\
\hline 1f & 370 & 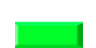 & 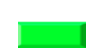 & 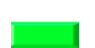 & 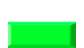 & 2.82 & -3.98 & -29.06 & 0.38 \\
\hline Ifosfamide $\left(\right.$ Holoxan $\left.^{\circledast}\right)$ & 260 & & $\square$ & $\square$ & 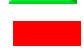 & 1.06 & $-1,89$ & $-10,7$ & 0.1 \\
\hline
\end{tabular}

Highly toxic —, Slightly toxic _, Not toxic —;

${ }^{[a]}$ MUT: Mutagenic, TUM: Tumorigenic, IRRIT: Irritant, RE: Reproductive effective. ${ }^{[b]}$ Sol: Solubility, DL: Druglikness, DS: Drug-Score 
Table 4. Molinspiration calculations of compounds (1a-1f)

\begin{tabular}{lccccccccccc}
\hline \multirow{2}{*}{ Compounds } & \multicolumn{3}{c}{ Molinspiration calculations ${ }^{[\mathrm{a}]}$} & \multicolumn{5}{c}{ Drug-likeness } \\
\cline { 2 - 10 } & TPSA & NONH & NV & VOL & GPCRL & ICM & KI & NRL & PI & EI \\
\hline 1a & 48 & 1 & 0 & 216 & -0.62 & 0.39 & -0.64 & -0.90 & 0.04 & 0.26 \\
1b & 48 & 1 & 0 & 232 & -0.52 & 0.25 & -0.69 & -0.86 & 0.06 & 0.27 \\
1c & 48 & 1 & 0 & 266 & -0.34 & 0.18 & 0.50 & -0.68 & 0.34 & 0.32 \\
1d & 48 & 1 & 0 & 282 & -0.22 & 0.21 & -0.44 & -0.43 & 0.46 & 0.37 \\
$\mathbf{1}^{\mathbf{e}}$ & 48 & 1 & 0 & 304 & -0.04 & 0.31 & -0.19 & -0.39 & 0.45 & 0.36 \\
1f & 63 & 1 & 0 & 333 & 0.15 & 0.37 & 0.04 & -0.35 & 0.45 & 0.41 \\
Ifosfamide(Holoxan $\left.^{\oplus}\right)$ & 42 & 1 & 0 & 209 & -0.71 & -0.45 & -0.65 & -1.02 & -0.29 & 0.55 \\
\hline
\end{tabular}

[a]TPSA: Total molecular polar surface area; NONH: number of OH---N or O---NH interaction, NV: number of violation of five Lipinsky rules; VOL: volume. ${ }^{[b]}$ GPCRL: GPCR ligand; ICM: Ion channel modulator; KI: Kinase inhibitor; NRL: Nuclear receptor ligand; PI: Protease inhibitor; EI: Enzyme inhibitor

In the docking study, the 6 compounds mentioned above were prepared using open babel [40] software and docked into the catalytic site of the human cytochrome P450 (Fig. 7). Docking studies revealed that oxazaphosphinanes derivatives prove interesting stability inside the cavity, with remarkable superimposition (Fig. 8). All compounds were ranked by the total energy of predicted pose in the binding site (Table 5). Otherwise, the 6 derivatives interact with active site residues mainly through hydrogen bonds, as well as hydrophobic interactions.

Compound 1f, which has the least binding total energy $(-41.319 \mathrm{kcal} / \mathrm{mol})$ is most favorable, with the most interesting interaction inside the pocket. Fig. 10 shows that compound $\mathbf{1 f}$ was docked to the pocket of human cytochrome P450. Compound 1 ff formed 4 hydrogen bonds

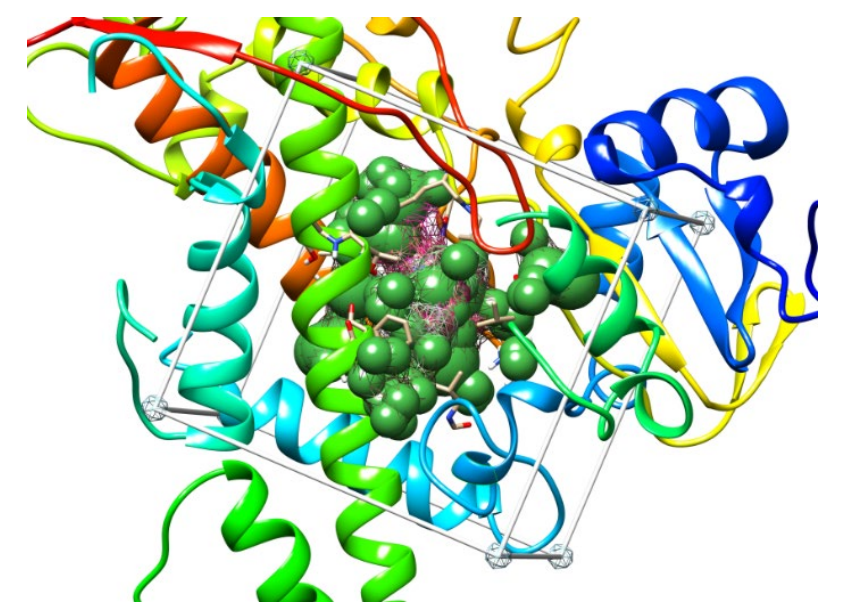

Fig 7. The active site of the human cytochrome P450 (Green spheres) with the residues of Cys437 and Thr303, 2 hydrogen bonds as a donor with the nitrogen atom, and 2 others as an acceptor with the oxygen atom. Otherwise, 3 hydrophobics interactions occur with the residues of Phe430, Phe298, and Ile115, which makes it the most stable ligand.

Table 5. Ranking of the six oxazaphosphinanes derivatives after docking study

\begin{tabular}{lcc}
\hline Compounds & Total energy $(\mathrm{kcal} / \mathrm{mol})$ & Docking score \\
\hline 1a & -22.892 & -4.728 \\
1b & -28.506 & -4.457 \\
1c & -32.58 & -5.112 \\
1d & -33.413 & -4.271 \\
1e & -38.496 & -6.219 \\
1f & -41.319 & -9.949 \\
Ref ligand (4PZ) & -37.21 & 7.123 \\
\hline
\end{tabular}

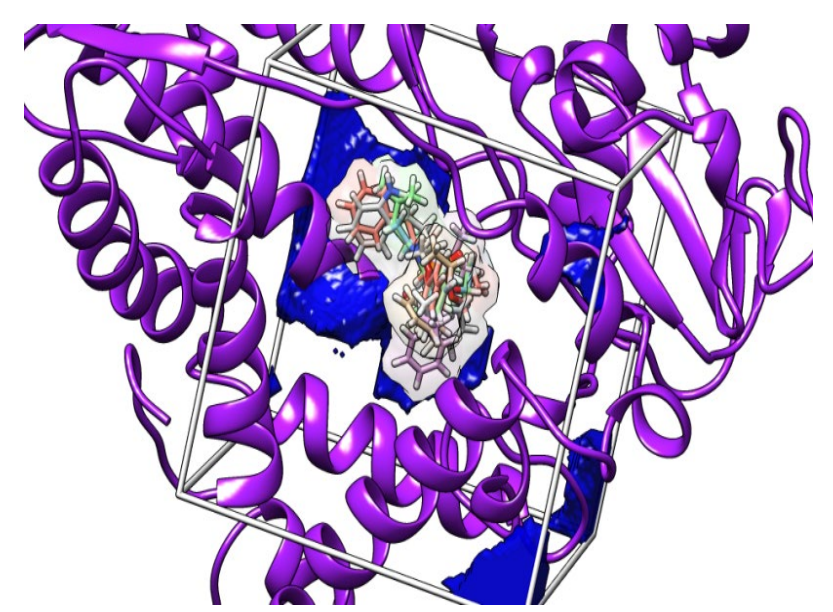

Fig 8. Super imposition of the six oxazaphosphinanes derivatives in the cavity after docking calculation 


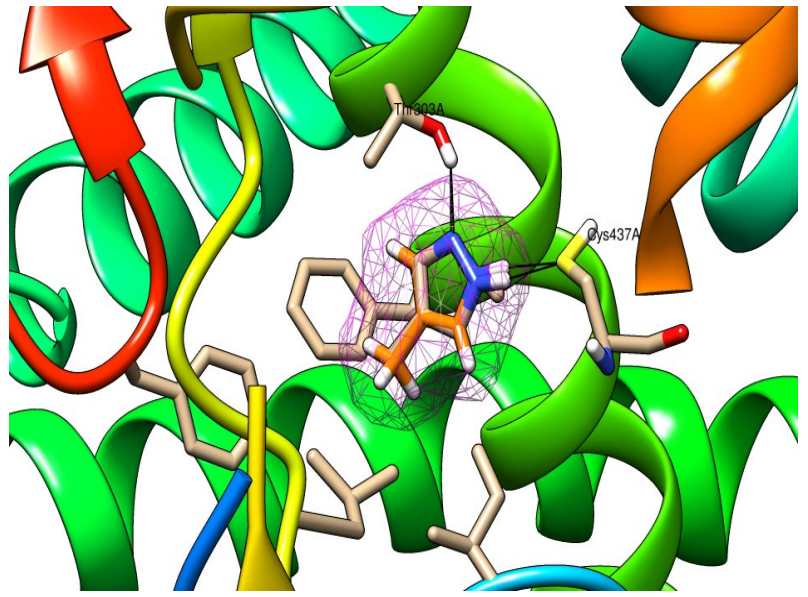

Fig 9. Conserved active site architecture after self-docking for the co-crystallized ligand (4PZ). Hydrogen bonding interactions are shown in black

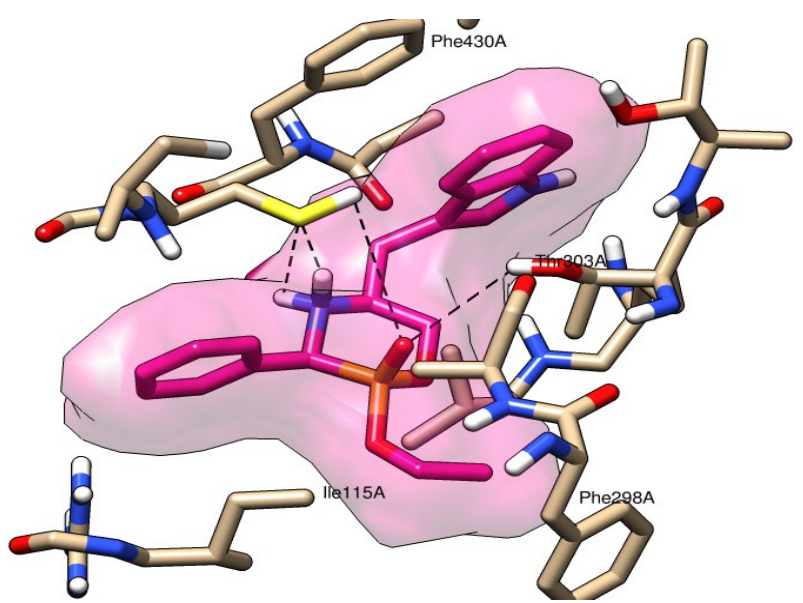

Fig 10. Binding model of compound $1 \mathrm{f}$ in the binding pocket of human cytochrome P450. The amino acid residues and compound $\mathbf{1 f}$ are shown as stick models, $\mathrm{H}$ bonds are shown as black dashed lines

Prior to the docking analysis, a self-docking evaluation of the main cytochrome-inhibitor X-ray complexes has been carried out using the Dock v6.9 program [41]. The use of this program resulted to be the most reliable as it showed the lower average root-meansquare deviation (RMSD) (Fig. 9).

\section{- CONCLUSION}

This work reports the computational analysis of a new series of oxazaphosphinane derivatives. The geometry of all synthesized compounds was optimized with DFT/B3LYP methods using 6-31G(d) basis to determine tasks that coordinate electron density with energy. Our findings reveal that all synthesized compounds, 1a-1f, are not toxic and can be utilized as therapeutic agents. All oxazaphosphinane derivatives represent an important antifungal $O, N$-pharmacophore site, which needs a separated supplementary antifungal screening. The nature of the pharmacophore site assignment of the oxazaphosphinane compounds was based on their docking and Petra/Osiris/Molinspiration (POM) analyses.

\section{- ACKNOWLEDGMENTS}

The General Directorate for Scientific Research and Technological Development (DG-RSDT), Algerian Ministry of Scientific Research, Applied Organic Laboratory (FNR 2000), financially supported this work.

\section{- REFERENCES}

[1] Masao, C., Kunitomo, A., Yoshihito, T., Kunio, S., Hirofumi, M., Ayumi, T., and Masatoshi, K., 2005, Phosphinane compounds with immunomodulating activity, PAT: WO2005014603.

[2] Zhang, H., Tsukuhara, R., Tigyi, G., and Prestwich, G.D., 2006, Synthesis of cyclic phosphonate analogues of (lyso)phosphatidic acid using a ringclosing metathesis reaction, J. Org. Chem., 71 (16), 6061-6066.

[3] Babouri, R., Rolland, M., Sainte-Catherine, O., Kabouche, Z., Lecouvey, M., Bakalara, N., Volle, J.N., Virieux, D., and Pirat, J.L., 2015, a-Halogenated oxaphosphinanes: Synthesis, unexpected reactions, and evaluation as inhibitors of cancer cell proliferation, Eur. J. Med. Chem., 104, 33-41.

[4] Hewitt, D.G., and Newland, G.L., 1977, Organo phosphorus compounds. P-Arylated perhydro-1,2azaphosphorines, Aust. J. Chem., 30 (3), 579-587.

[5] Shipov, A.E., Genkina, G.K., Petrovskii, P.V., Goryunov, E.I., and Makarov, M.V., 2011, Novel biologically active 1,3,2-oxazaphosphinane derivatives, Phosphorus Sulfur Silicon Relat. Elem., 186 (4), 945-951.

[6] Gilard, V., Martino, R., Malet-Martino, M., Niemeyer, U., and Pohl, J., 1999, Chemical stability 
and fate of the cytostatic drug ifosfamide and its $\mathrm{N}$ dichloroethylated metabolites in acidic aqueous solutions, J. Med. Chem., 42 (14), 2542-2560.

[7] Volle, J.N., Kaloyanov, N., Saada, M.C., Virieux, D., and Pirat, J.L., 2007, Phosphinyl analogues of hydroxybupropion: ( \pm )-2-aryl-3,3,5,5-tetramethyl[1,4,2]-oxazaphosphinanes, Tetrahedron Lett., 48 (27), 4695-4697.

[8] Silverman, R.B., 2004, The Organic Chemistry of Drug Design and Drug Action, $2^{\text {nd }}$ Ed., Academic Press, Burlington, Massachusetts.

[9] Tarakeshwar, P, Kim, D, Lee, H.M., Suh, S.B., and Kim, K.S., 2004, "Theoretical approaches to the design of functional nanomaterials" in Computational Materials Science, Vol. 15, Eds. Leszczynski, J., Elsevier B.V., Amsterdam, Netherlands, 119-170.

[10] Lakshmanan, A., McBrien, A., Zhang, J., and Dhole, V., 2014, Transformation of process engineering - A software perspective, Comput. Aided Chem. Eng., 34, 186-195.

[11] Fleming, I., 2010, Molecular Orbitals and Organic Chemical Reactions-Reference Edition, John Wiley \& Sons, Chichester, United Kingdom.

[12] Boufas, W., Dupont, N., Berredjem, M., Berrezag, K., Becheker, I., Berredjem, H., and Aouf, N.E., 2014, Synthesis and antibacterial activity of sulfonamides. SAR and DFT studies, J. Mol. Struct., 1074, 180-185.

[13] Cheloufi, H., Bechlem, K., Boufas, W., Barbey, C., Bouzina, A., Belhani, B., Dupont, N., Aouf, N.E., and Berredjem, M., 2017, Synthesis, X-ray crystallographic and DFT studies of two new $N$-acylsulfonamides, $J$. Mater. Environ. Sci., 8 (3), 997-1003.

[14] Rachedi, K.O., Ouk, T.S., Bahadi, R., Bouzina, A., Djouad, S.E., Bechlem, K., Zerrouki, R., Ben Hadda, T., Almalki, F., and Berredjem, M., 2019, Synthesis, DFT and POM analyses of cytotoxicity activity of $\alpha-$ amidophosphonates derivatives: Identification of potential antiviral O,O-pharmacophore site, J. Mol. Struct., 1197, 196-203.

[15] Schuster, I., Koch, A., Heydenreich, M., Kleinpeter, E., Lázár, L., and Fülöp, F., 2008, Synthesis and conformational analysis of phenyl-substituted 1,3,2- oxazaphosphino[4,3-a]- and 1,2,3-oxathiazino[4,3a] isoquinolines, J. Mol. Struct., 888 (1-3), 124-137.

[16] Cristau, H.J., Pirat, J.L., Virieux, D., Monbrun, J., Ciptadi, C., and Bekro, Y.A., 2005, Synthesis, reactivity and stereochemistry of new phosphorus heterocycles with 5- or 6-membered rings, J. Organomet. Chem., 690 (10), 2472-2481.

[17] Belhani, B., Bouzina, A., Berredjem, M., and Aouf, N.E., 2015, One-pot synthesis of novel oxazaphosphinanes under ultrasound irradiation and solvent-free conditions, Monatsh. Chem., 146 (11), 1871-1875.

[18] Lee, C., Yang, W., and Parr, R.G., 1988, Development of the Colle-Salvetti correlation-energy formula into a functional of the electron density, Phys. Rev. B: Condens. Matter, 37 (2), 785-789.

[19] Organic Chemistry Portal, 2012, http://www.organicchemistry.org/prog/peo/, accessed on 15 January 2016.

[20] Lourenço, A.L.P.G., Vegi, P.F., Faria, J.V., Pinto, G.S.P., dos Santos, M.S., Sathler, P.C., Saito, M.S., Santana, M., Dutra, T.P.P., Rodrigues, C.R., Monteiro, R.Q., Bernardino, A.M.R., and Castro, H.C., 2019, Pyrazolyl-tetrazoles and imidazolylpyrazoles as potential anticoagulants and their integrated multiplex analysis virtual screening, $J$. Braz. Chem. Soc., 30 (1), 33-47.

[21] DesJarlais, R.L., Sheridan, R.P., Seibel, G.L., Dixon, J.S., Kuntz, I.D., and Venkataraghavan, R., 1988, Using shape complementarity as an initial screen in designing ligands for a receptor binding site of known three-dimensional structure, J. Med. Chem., 31 (4), 722-729.

[22] Kuntz, I.D., 1992, Structure-based strategies for drug design and discovery, Science, 257 (5073), 1078-1082.

[23] Mukherjee, S., Balius, T.E., and Rizzo, R.C., 2010, Docking validation resources: Protein family and ligand flexibility experiments, J. Chem. Inf. Model., 50 (11), 1986-2000.

[24] Frisch, M.J., Trucks, G.W., Schlegel, H.B., Scuseria, G.E., Robb, M.A., Cheeseman, J.R., Scalmani, G., 
Barone, V., Petersson, G.A., Nakatsuji, H., Li, X., Caricato, M., Marenich, A., Bloino, J., Janesko, B.G., Gomperts, R., Mennucci, B., Hratchian, H.P., Ortiz, J.V., Izmaylov, A.F., Sonnenberg, J.L., WilliamsYoung, D., Ding, F., Lipparini, F., Egidi, F., Goings, J., Peng, B., Petrone, A., Henderson, T., Ranasinghe, D., Zakrzewski, V.G., Gao, J., Rega, N., Zheng, G., Liang, W., Hada, M., Ehara, M., Toyota, K., Fukuda, R., Hasegawa, J., Ishida, M., Nakajima, T., Honda, Y., Kitao, O., Nakai, H., Vreven, T., Throssell, K., Montgomery, J.A., Jr., Peralta, J.E., Ogliaro, F., Bearpark, M., Heyd, J.J., Brothers, E., Kudin, K.N., Staroverov, V.N., Keith, T., Kobayashi, R., Normand, J., Raghavachari, K., Rendell, A., Burant, J.C., Iyengar, S.S., Tomasi, J., Cossi, M., Millam, J.M., Klene, M., Adamo, C., Cammi, R., Ochterski, J.W., Martin, R.L., Morokuma, K., Farkas, O., Foresman, J.B., and Fox, D.J., 2016, Gaussian 09, Revision A.02, Gaussian 09 Inc., Wallingford CT.

[25] Becke. A.D., 1993, Density-functional thermo chemistry. III. The role of exact exchange, J. Chem. Phys., 98 (7), 5648-5652.

[26] Francl, M.M., Pietro, W.J., Hehre, W.J., Binkley, J.S., Gordon, M.S., DeFrees, D.J., and Pople, J.A., 1982, Self-consistent molecular orbital methods. XXIII. A polarization-type basis set for second-row elements, J. Chem. Phys., 77 (7), 3654-3665.

[27] Pauling, L., 1932, The nature of the chemical bond. IV. The energy of single bonds and the relative electronegativity of atoms, J. Am. Chem. Soc., 54 (9), 3570-3582.

[28] Pearson, R.G., 2005, Chemical hardness and density functional theory, J. Chem. Sci., 117 (5), 369-377.

[29] Parr, R.G., Szentpály, L.V., and Liu, S., 1999, Electrophilicity index, J. Am. Chem. Soc., 121 (9), 1922-1924.

[30] Mabkhot, Y.N., Alatibi, F., El-Sayed, N., AlShowiman, S., Kheder, N.A., Wadood, A., Rauf, A., Bawazeer, S., and Ben Hadda, T.B., 2016, Antimicrobial activity of some novel armed thiophene derivatives and petra/osiris/molinspiration (POM) analyses, Molecules, 21 (2), 222-238.

[31] Mabkhot, Y.N., Arfan, M., Zgou, H., Genc, Z.K., Genc,
M., Rauf, A., Bawazeer, S., and Hadda, T.B., 2016, How to improve antifungal bioactivity: POM and DFT study of some chiral amides derivatives of diacetyl-L-tartaric acid and amines, Res. Chem. Intermed., 42 (12), 8055-8068.

[32] Sajid, Z., Ahmad, M., Aslam, S., Ashfaq, U.A., Zahoor, A.F., Saddique, F.A., Parvez, M., Hameed, A., Sultan, S., Zgou, H., and Hadda, T.B., 2016, Novel armed pyrazolobenzothiazine derivatives: Synthesis, X-ray crystal structure and POM analyses of biological activity against drug resistant clinical isolate of Staphylococcus aureus, Pharm. Chem. J., 50 (3), 172-180.

[33] Ooms, F., 2000, Molecular modeling and computer aided drug design. Examples of their applications in medicinal chemistry, Curr. Med. Chem., 7 (2), 141158.

[34] Shoichet, B.K., 2004, Virtual screening of chemical libraries, Nature, 432 (7019), 862-865.

[35] Jorgensen, W.L., 2004, The many roles of computation in drug discovery, Science, 303 (5665), 1813-1818.

[36] Aouad, M.R., Mayaba, M.M., Naqvi, A., Bardaweel, S.K., Al-Blewi, F.F., Messali, M., and Rezki, N., 2017, Design, synthesis, in silico and in vitro antimicrobial screenings of novel 1,2,4-triazoles carrying 1,2,3-triazole scaffold with lipophilic side chain tether, Chem. Cent. J., 11 (1), 117.

[37] Hashemi, S.M., Badali, H., Faramarzi, M.A., Samadi, N., Afsarian, M.H., Irannejad, H., and Emami, S., 2015, Novel triazole alcohol antifungals derived from fluconazole: Design, synthesis, and biological activity, Mol. Diversity, 19 (1), 15-27.

[38] Wu, J., Ni, T., Chai, X., Wang, T., Wang, H., Chen, J., Jin, Y., Zhang, D., Yu, S., and Jiang, Y., 2018, Molecular docking, design, synthesis and antifungal activity study of novel triazole derivatives, Eur. J. Med. Chem., 143, 1840-1846.

[39] Sastry, G.M., Adzhigirey, M., Day, T., Annabhimoju, R., and Sherman, W., 2013, Protein and ligand preparation: Parameters, protocols, and influence on virtual screening enrichments, J. Comput.-Aided Mol. Des., 27 (3), 221-234. 
[40] O'Boyle, N.M., Banck, M., James, C.A., Morley, C., Vandermeersch, T., and Hutchison, G.R., 2011, Open Babel: An open chemical toolbox, J. Cheminf., 3,33 .
[41] Kuntz, I.D., Blaney, J.M., Oatley, S.J., Langridge, R., and Ferrin, T.E., 1982, A geometric approach to macromolecule-ligand interactions, J. Mol. Biol., 161 (2), 269-288. 